\title{
Primary effusion lymphoma associated with Human Herpes Virus-8 and Epstein Barr virus in an HIV-infected woman from Kampala, Uganda: a case report
}

Lynnette K Tumwine ${ }^{1 *}$, Rejani Lalitha ${ }^{2}$, Claudio Agostinelli ${ }^{3}$, Simon Luzige ${ }^{2}$, Jackson Orem ${ }^{4}$, Pier Paolo Piccaluga ${ }^{3}$, Lawrence $O$ Osuwat ${ }^{1}$, Stefano A Pileri ${ }^{3}$

\begin{abstract}
Introduction: Primary effusion lymphoma is a recently recognized entity of AIDS related non-Hodgkin lymphomas. Despite Africa being greatly affected by the HIV/AIDS pandemic, an extensive MEDLINE/PubMed search failed to find any report of primary effusion lymphoma in sub-Saharan Africa. To our knowledge this is the first report of primary effusion lymphoma in sub-Saharan Africa. We report the clinical, cytomorphologic and immunohistochemical findings of a patient with primary effusion lymphoma.
\end{abstract}

Case presentation: A 70-year-old newly diagnosed HIV-positive Ugandan African woman presented with a threemonth history of cough, fever, weight loss and drenching night sweats. Three weeks prior to admission she developed right sided chest pain and difficulty in breathing. On examination she had bilateral pleural effusions. Haematoxylin and eosin stained cytologic sections of the formalin-fixed paraffin-embedded cell block made from the pleural fluid were processed in the Department of Pathology, Makerere University, College of Health Sciences, Kampala, Uganda. Immunohistochemistry was done at the Institute of Haematology and Oncology "L and A Seragnoli", Bologna University School of Medicine, Bologna, Italy, using alkaline phosphatase anti-alkaline phosphatase method. In situ hybridization was used for detection of Epstein-Barr virus.

The tumor cells were CD45+, CD30+, CD38+, HHV-8 LANA-1+; but were negative for CD3-, CD20-, CD19-, and CD79a- and EBV RNA+ on in situ hybridization. CD138 and Ki-67 were not evaluable. Our patient tested HIV positive and her CD4 cell count was 127/ $\mu \mathrm{L}$.

Conclusions: A definitive diagnosis of primary effusion lymphoma rests on finding a proliferation of large immunoblastic, plasmacytoid and anaplastic cells; HHV-8 in the tumor cells, an immunophenotype that is CD45 + , pan B-cell marker negative and lymphocyte activated marker positive. It is essential for clinicians and pathologists to have a high index of suspicion of primary effusion lymphoma when handling HIV positive patients who have effusions without palpable tumor masses. Basic immunohistochemistry is essential for definitive diagnosis.

\footnotetext{
* Correspondence: tumwinelynnette@yahoo.com

'Department of Pathology, School of Biomedical Sciences, Makerere University College of Health Sciences, Mulago Hill Road, PO Box 7072, Kampala, Uganda

Full list of author information is available at the end of the article
} 


\section{Introduction}

Primary effusion lymphoma (PEL) is a rare aggressive B-cell lymphoma which was first identified in 1989 as a subset of body-cavity-based lymphomas $[1,2]$. It accounts for only $0.13 \%$ of all AIDS related malignancies among AIDS patients in the USA [3]. The WHO classification recognizes it as a unique entity of non-Hodgkin lymphoma (NHL) [2].

It has been suggested that Kaposi sarcoma herpes virus/Human herpes virus-8 (KSHV/HHV-8) is the causative agent of PEL. In Europe and America very high seroprevalences of HHV-8 (around 67\%) have been reported among HIV-positive men who have sex with men [4]. It was initially thought that the transmission in Western countries was sexual [5], however, a recent study in Texas showed high HHV-8 seroprevalences of $26 \%$ among children, indicating another mode of transmission of HHV-8 [6].

In Africa, studies have shown considerable variation in the seroprevalence rates of HHV-8 infection among adults and children; the highest adult rates of $26-100 \%$ have been found in Uganda, Cameroon, Ivory Coast, Gambia, the Democratic Republic of Congo, Tanzania, Zambia and South Africa.

Nigeria, Ghana, Zimbabwe and Egypt have prevalence rates of $50 \%$ and the countries with relatively low rates of $25 \%$ and below are the Central African Republic, Eritrea and Senegal [7].

A recent study revealed increasing seroprevalence of HHV-8 with age among Ugandan children, from 10\% among two-year-olds to $36.4 \%$ in eight-year-olds, in contrast to South African children where there were seroprevalence rates of $7.5-9 \%$ [8].

In East and Central Africa, the HHV-8 seroprevalence reaches $80 \%$ in the adult population. In Uganda, HHV-8 seroprevalence is approximately $40 \%$ in adulthood and studies have also confirmed transmission by blood transfusion $[9,10]$.

In sub-Saharan Africa, there have been very few reports of PEL and this is probably because effusions are often not made into cell blocks, and even when they are, no immunohistochemistry is performed $[11,12]$. Hence, it is possible that PEL is being missed as an important subtype of AIDS-related NHL [13]. Despite HIV, EpsteinBarr virus (EBV) and HHV-8 being endemic in Uganda, no case of PEL has, before now, been reported from the country. We report a case of PEL in a 70-year-old HIVinfected woman from Kampala, Uganda.

\section{Case presentation}

A 70-year-old newly diagnosed HIV-positive Ugandan African woman presented with a three-month history of cough, fever, weight loss and drenching night sweats.
Three weeks prior to admission she developed right sided chest pain and difficulty in breathing. There was no history of haemoptysis or bleeding from any site. She had occasional palpitations. There was no history of leg swelling, orthopnea or paroxysmal nocturnal dyspnoea. She had been vomiting for two days prior to admission, but had no oral sores or alteration in bowel habits. A review of the rest of her systems was unremarkable.

This was her first admission to hospital; she reported having been unwell for three months and had received treatment for cough from a nearby clinic. As she was newly diagnosed with HIV, she had not yet received cotrimoxazole or highly active antiretroviral therapy (HAART).

She was nulliparous, had never married but had had several sexual partners. She had been smoking a pipe (with tobacco); however, she denied alcohol consumption.

On examination, she was elderly, sick looking, with severe pallor, dehydration and wasting. She had no lymphadenopathy, jaundice, or edema. Her liver, spleen and kidneys were not palpable. She had no Kaposi sarcoma lesions on her skin or mucus membranes. She had tachycardia (92 beats per minute) with apparently normal heart sounds but she had a functional systolic murmur. Her blood pressure was $125 / 90 \mathrm{mmHg}$. She had tachypnoea ( 35 breaths per minute), reduced air entry and fine crackles on the right side of her chest.

Results of laboratory investigations are shown in table 1 . A chest $x$-ray showed bilateral pleural effusions and subcutaneous emphysema. Echocardiography showed a mild pericardial effusion.

On ultrasonography, her liver, spleen, kidney and pancreas were normal in size, shape and echo pattern. Her urinary bladder wall was normal. There was no ascites or lymphadenopathy. Bilateral large pleural effusions were confirmed. No solid tumor masses were present.

Table 1 Results of laboratory investigations

\begin{tabular}{lll}
\hline Laboratory test & Result & Normal range \\
\hline Serum creatinine & $172 \mu \mathrm{mol} / \mathrm{L}$ & $44-106 \mu \mathrm{mol} / \mathrm{L}$ \\
\hline Alanine aminotransferase & 8.8 I Units/L & $0-41$ I Units $/ \mathrm{L}$ \\
\hline Serum calcium & $2.0 \mathrm{mmol} / \mathrm{L}$ & $2.2-2.6 \mathrm{mmol} / \mathrm{L}$ \\
\hline Potassium & $6.3 \mathrm{mmol} / \mathrm{L}$ & $3.5-5.5 \mathrm{mmol} / \mathrm{L}$ \\
\hline Sodium & $151.2 \mathrm{mmol} / \mathrm{L}$ & $135-150 \mathrm{mmol} / \mathrm{L}$ \\
\hline WBC (total) & $8.5 \times 10^{3} / \mu \mathrm{L}$ & $4-11 \times 10^{3} / \mu \mathrm{L}$ \\
\hline Neutrophils & $62.5 \%$ & $45-70 \%$ \\
\hline Lymphocytes & $22.0 \%$ & $20-40 \%$ \\
\hline Monocytes & $14.4 \%$ & $3-10 \%$ \\
\hline Platelets & $219 \times 10^{3} / \mu \mathrm{L}$ & $150-400 \times 10^{3} / \mu \mathrm{L}$ \\
\hline Haemoglobin & $6.8 \mathrm{~g} / \mathrm{Dl}$ & $12-18 \mathrm{~g} / \mathrm{dL}$ \\
\hline CD4 cell count & $127 / \mu \mathrm{L}$ & $410-1590 / \mu \mathrm{L}$ \\
\hline CD8 cell count & $1178 / \mu \mathrm{L}$ & $190-1140 / \mu \mathrm{L}$ \\
\hline
\end{tabular}


A sample of about $150 \mathrm{ml}$ of pleural fluid was taken from her right hemithorax and sent to the Department of Pathology, Makerere University, College of Health Sciences, Kampala, Uganda, where it was cytocentrifuged. The sediment was made into a cell block and haematoxylin and eosin stained slides revealed a neoplastic proliferation of large lymphoid cells with round to irregular nuclei, prominent nucleoli, and varying amounts of vacuolated cytoplasm. There were immunoblastic, plasmablastic and anaplastic variants with bizarre, pleomorphic nuclei (Figure 1A). They included multinucleated and Reed-Sternberg-like cells. From these findings a preliminary diagnosis of PEL was made.

Since immunohistochemistry is not routinely available in Uganda, it was carried out at the Institute of Haematology and Oncology "L and A Seragnoli", Bologna University School of Medicine, Bologna, Italy. The alkaline phosphatase anti-alkaline phosphatase method and the primary antibodies listed in table 2 were used. In situ hybridization was also used for detection of EBV. The tumor cells were CD45+ (Figure 1C), CD30+, CD38+, HHV-8 LANA-1+ (Figure 1D); but were negative for CD3-, CD20- (Figure 1B), CD19-, and CD79aand EBV RNA+ (Figure $1 \mathrm{C}$ inset) on in situ hybridization. CD138 and Ki-67 were not evaluable. These findings confirmed the diagnosis of PEL. The patient tested HIV-positive and her CD4 cell count was $127 / \mu \mathrm{L}$.

Treatment: She was initially rehydrated with normal saline and 5\% dextrose, and later received a blood transfusion. She also received allopurinol, ceftriaxone and metronidazole. After she had stabilized, she was given the first course of chemotherapy with a CHOP protocol

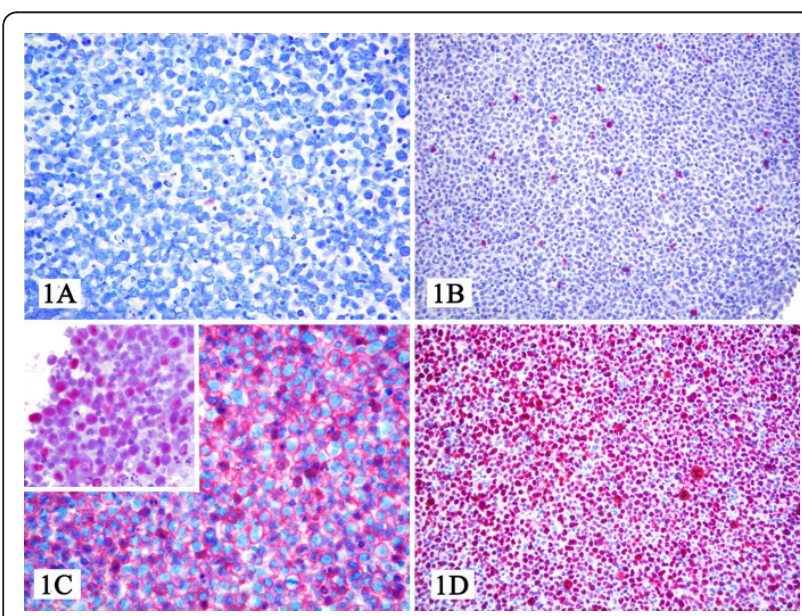

Figure 1 At light microscopy, the sample consisted of a frankly neoplastic population provided with plasmablastic and/or anaplastic morphology (Figure 1A), which turned out CD3-, CD20- (Figure 1B), CD79a-, CD45+ (Figure 1C), CD38+, CD30+, IRF4+, LANA-1+ (Figure 1D), EBER+ (Figure 1C inset), and Ki$67>90 \%$. Based on these findings, we made a diagnosis of PEL.
Table 2 Primary antibodies used for diagnosis

\begin{tabular}{lllll}
\hline Antibody & Clone & Source & Antigen retrieval & Dilution \\
\hline CD45 & LCA & Dako & EDTA 750 W & 1:100 \\
\hline CD3 & SP7 & Immunotech & EDTA 750 W & $1: 250$ \\
\hline CD20 & L26 & Dako & EDTA 750 W & $1: 200$ \\
\hline CD30 & Ber- H2 & Prof. B Falini* & EDTA 900 W & $1: 3$ \\
\hline CD38 & SPC32 & Novocastra & EDTA 750 W & $1: 10$ \\
\hline CD79a & JCB117 & Prof. D Mason & EDTA 750 W & $1: 10$ \\
\hline HHV8 & 13B10 & Menarini & EDTA 750 W & $1: 10$ \\
\hline CD138 & - & Neomarkers & EDTA 900 W & $1: 20$ \\
\hline Ki-67 & Mib-1 & Dako & EDTA 900 W & $1: 20$ \\
\hline
\end{tabular}

*Kindly provided by Prof. Brunangelo Falini, Perugia University, Perugia, Italy. ${ }^{\S}$ Kindly provided by Prof. David Y Mason, Oxford University, Oxford, UK.

(cyclophosphamide $750 \mathrm{mg} / \mathrm{m}^{2}$, Adriamycin (doxorubicin) $50 \mathrm{mg} / \mathrm{m}^{2}$ and Oncovin (vincristine) $14 \mathrm{mg} / \mathrm{m}^{2}$ on day one and prednisolone $100 \mathrm{mg}$ on days one to five, repeated every 21 days). In addition, she received omeprazole, metoclopramide and dexamethasone. She registered some improvement after the first course of chemotherapy and was allowed home. She was discharged through the Infectious Disease Institute clinic to be initiated on HAART. She was due to return for subsequent anti-cancer treatment but died two days after discharge from our hospital.

\section{Discussion}

We have reported the case of a patient who presented with all the features of PEL that have been described elsewhere $[14,15]$. This was the first AIDS defining illness in this patient even though she had very low CD4 counts.

The strong positivity for HHV-8 in this patient is similar to what other authors have found in studies on HIV-positive PEL patients [14,16]. HHV-8, by definition, has to be present in the tumor cells in order to make a diagnosis of PEL [15]. The co-infection of HHV -8 and EBV in this patient is interesting. Both HHV-8 and EBV are $\gamma$-herpes viruses and are closely related. While evidence of HHV-8 is essential for diagnosis of PEL, the role of HHV-8 in the pathogenesis is not clear. However, we know that EBV immortalizes B-cells while HHV-8 seems not to. It would, therefore, appear that HHV-8 by itself is not sufficient for the development of PEL. It seems that EBV causes unchecked proliferation of B-cells leading to development of PEL and, according to Fan and others, "once PELs have developed HHV-8 appears to be the driving force [14]." Recently, several cases of EBV negative PEL have been reported implying that HHV-8 plays a critical role in pathogenesis [17].

About 31 cases of HHV-8 independent PEL (HHV-8unrelated PEL-like lymphoma) have been reported in 
the literature [18]. This new entity is now referred to more precisely as HHV-8-unrelated large B-cell lymphomas because of the differences observed in its pathogenesis, morphology and immunophenotype (it expresses a B-cell phenotype unlike PEL), and is associated with hepatitis $C$ virus infection in $30-40 \%$ of cases [19]. The clinical behavior and prognosis are significantly different from that of PEL patients. The HHV-8-unrelated large B-cell lymphoma patients tend to have more indolent disease that has been observed to resolve spontaneously and, when treated, these patients have a much better prognosis than the HIV-positive, HHV-8 positive PEL patients - who have a very poor outcome [19]. This therefore proves that the two are separate entities.

PEL, possibly uniquely, presents as serous effusions in the pleural, peritoneal and pericardial cavity without identifiable tumor masses or lymphadenopathy.

The morphological presentation is as a large B-cell neoplasm and the tumor cells contain KSHV/HHV-8 DNA and lack c-myc translocations. PEL most commonly affects male AIDS patients and was first recognized in men who have sex with men [20,21]. However, a few cases have been reported in women. It is easily distinguished from other lymphomas because of its unusual morphology with large immunoblastic, plasmacytoid and/or anaplastic cells.

The immunophenotypical presentation of PEL cells is typically as a "null" lymphocyte phenotype, meaning that CD45 is expressed, but routine B-cell (including surface and cytoplasmic immunoglobulin, CD19, CD20, CD79a) and T-cell (CD3, CD4, CD8) markers are absent. Instead, various markers of lymphocyte activation (CD30, CD38, CD71, human leukocyte antigen DR) and plasma cell differentiation (CD138) are usually displayed [22].

PELs are of B-cell origin because they have clonal immunoglobulin gene rearrangements [17,23].

Although immunohistochemical services are not routinely available in Uganda and other resource constrained countries, it is still possible to suspect PEL with available clinical and cytomorphologic criteria. These include lymphomatous effusions limited to the body cavities with no solid tumor or lymphadenopathy and pleomorphic large cells with immunoblastic, plasmacytoid and anaplastic variants [20].

Regarding PEL, no optimal treatment has yet been identified [24]. Most HIV-positive PEL patients receive anthracycline-based multiagent chemotherapy (CHOP; cyclophosphamide, doxorubicin, vincristine, and prednisone) and antiretroviral therapy. Patients with HHV-8 negative large B-cell lymphomas have been shown to benefit from immunotherapy with rituximab since they display B-cell immunophenotype, pleurodesis and thoracocentesis [25]. However, in resource poor settings such as Uganda only $\mathrm{CHOP}$ and antiretroviral agents are used [18]. NF-kappa B plays a significant role in PEL oncogenesis. Studies using new drug regimens directed against NF-kappa B have shown positive results. These drugs are currently being developed for therapeutic use $[26,27]$.

\section{Conclusions}

Since a definitive diagnosis of PEL rests on the presence of HHV-8 in the tumor cells, a lymphoproliferation of large immunoblastic, plasmacytoid and/or anaplastic cells, an immunophenotype of leucocyte common antigen CD45 positive, pan B-cell marker negative, and lymphocyte activated marker (CD 138, CD30, CD38, human leukocyte antigen DR and CD71) positive, it is essential for clinicians and pathologists to develop a high index of suspicion of PEL when handling HIV-positive patients with effusions without palpable tumor masses. Basic immunohistochemistry to confirm the diagnosis is necessary.

\section{Abbreviations}

CD: Cluster of differentiation; CHOP: anthracycline-based multiagent chemotherapy (cyclophosphamide, doxorubicin, vincristine, and prednisone); EBER: Epstein-Barr virus encoded RNA; EBV: Epstein-Barr virus; HAART: highly active antiretroviral therapy; HIV: human immunodeficiency virus; HHV-8: human herpesvirus 8; KSHV: Kaposi sarcoma herpes virus; LANA-1: Lymphoma associated nuclear antigen-1; NHL: non-Hodgkin lymphoma; PEL: primary effusion lymphoma; WBC: white blood cell count; WHO: World Health Organization.

\section{Acknowledgements}

Supported by a grant from BologAlL and Gruppo Delta (Bologna, Italy) for the scientific and technological development of the Department of Pathology of Makerere University.

\section{Author details}

${ }^{1}$ Department of Pathology, School of Biomedical Sciences, Makerere University College of Health Sciences, Mulago Hill Road, PO Box 7072 , Kampala, Uganda. ${ }^{2}$ Department of Medicine, School of Medicine, Makerere University College of Health Sciences, Mulago Hill Road, PO Box 7072, Kampala, Uganda. ${ }^{3}$ Unit of Hematopathology, Department of Haematology and Oncological Sciences "L and A Seràgnoli", S Orsola- Malpighi Hospital, University of Bologna, Bologna, Italy. ${ }^{4}$ Uganda Cancer Institute, PO Box 3935, Kampala, Uganda.

\section{Authors' contributions}

LKT conceived the idea, made preliminary diagnosis of PEL, and wrote the manuscript. CA carried out immunohistochemistry and in situ hybridization. $\mathrm{RL}, \mathrm{SL}$, and $\mathrm{JO}$ admitted and treated the patient, contributed patient data and revised the manuscript. LOO did cytotechnology and revised the manuscript. PPP and SAP reviewed and revised the manuscript. All authors read and approved the final version of the manuscript.

\section{Consent}

Written informed consent was obtained from the patient's next-of-kin for publication of this case report and any accompanying images. A copy of the written consent is available for review by the Editor-in-Chief of this journal.

\section{Competing interests}

The authors declare that they have no competing interests.

Received: 12 February 2010 Accepted: 14 February 2011

Published: 14 February 2011 


\section{References}

1. Carbone A, Gloghini A: KSHV/HHV8-associated lymphomas. Br J Haematol 2008, 140(1):13-24

2. Jaffe ES, Harris NL, Stein H, Vardiman JW, (Eds): World Health Organization Classification of tumors. Pathology and Genetics of tumors of haematopoietic and lymphoid tissues Lyon, France: IARC Press; 2001.

3. Mounier N, Spina M, Gabarre J, Raphael M, Rizzardini G, Golfier JB, Vaccher E, Carbone A, Coiffier B, Chichino G, Bosly A, Tirelli U, Gisselbrecht C: AIDSrelated non-Hodgkin lymphoma: final analysis of 485 patients treated with risk-adapted intensive chemotherapy. Blood 2006, 107(10):3832-3840.

4. Guanira J, Guanira JV, Casper C, Lama JR, Morrow R, Montano SM, Caballero P, Suárez L, Whittington WL, Wald A, Sanchez J, Celum C, Peruvian HIV Sentinel Surveillance Working Group: Prevalence and correlates of human herpesvirus 8 infection among Peruvian men who have sex with men. J Acquir Immune Defic Syndr 2008, 49(5):557-562.

5. Ablashi D, Chatlynne L, Cooper H, Thomas D, Yadav M, Norhanom AW, Chandana AK, Churdboonchart V, Kulpradist SA, Patnaik M, Liegmann K, Masood R, Reitz M, Cleghorn F, Manns A, Levine PH, Rabkin C, Biggar R, Jensen F, Gill P, Jack N, Edwards J, Whitman J, Boshoff C: Seroprevalence of human herpesvirus-8 (HHV-8) in countries of Southeast Asia compared to the USA, the Caribbean and Africa. Br J Cancer 1999, 81(5):893-897.

6. Baillargeon J, Leach CT, Deng JH, Gao SJ, Jenson HB: High prevalence of human herpesvirus 8 (HHV-8) infection in south Texas children. J Med Virol 2002, 67(4):542-548.

7. Sarmati L: HHV-8 infection in African children. Herpes 2004, 11(2):50-53

8. Butler LM, Dorsey G, Hladik W, Rosenthal PJ, Brander C, Neilands TB, Mbisa G, Whitby D, Kiepiela P, Mosam A, Mzolo S, Dollard SC, Martin JN: Kaposi sarcoma-associated herpesvirus (KSHV) seroprevalence in population-based samples of African children: evidence for at least 2 patterns of KSHV transmission. J Infect Dis 2009, 200(3):430-438.

9. Dollard SC, Butler LM, Jones AM, Mermin JH, Chidzonga M, Chipato T, Shiboski CH, Brander C, Mosam A, Kiepiela P, Hladik W, Martin JN: Substantial regional differences in human herpesvirus 8 seroprevalence in sub-saharan Africa: Insights on the origin of the "KS Belt". Int J Cancer 2010, 127(10):2395-2401.

10. Hladik W, Dollard SC, Mermin J, Fowlkes AL, Downing R, Amin MM, Banage F, Nzaro E, Kataaha P, Dondero TJ, Pellett PE, Lackritz EM: Transmission of human herpesvirus 8 by blood transfusion. N Eng J Med 2006, 355(13):1331-1338.

11. Cool C, Bitter M: The malignant lymphomas of Kenya; morphology, immunophenotype, and frequency of Epstein-Barr virus in 73 cases. Hum Pathol 1997, 28(9):1026-1033.

12. Lazzi S, Bellan C, Amato T, Palummo N, Cardone C, D’Amuri A, De Luca F, Beyanga M, Facchetti F, Tosi P, Leoncini L: Kaposi's sarcoma-associated herpesvirus/human herpesvirus 8 infection in reactive lymphoid tissues: a model for KSHV/HHV-8-related lymphomas? Hum Pathol 2006, 37(1):23-31.

13. Mwanda O, Remick S, Whalen C: Adult Burkitt's lymphoma in patients with and without human immunodeficiency virus infection in Kenya. Int J Cancer 2001, 92(5):687-691.

14. Fan W, Bubman D, Chadman A, Harrington WJ Jr, Cesarman E, Knowles DM: Distinct subsets of primary effusion lymphoma can be identified based on their cellular gene expression profile and viral association. J Virol 2005, 79(2):1244-51.

15. Mbulaiteye SM, Biggar RJ, Bakaki PM, Pfeiffer RM, Whitby D, Owor AM, Katongole-Mbidde E, Goedert JJ, Ndugwa CM, Engels EA: Human herpes virus 8 infection and transfusion history in children with sickle cell disease in Uganda. J Natl Cancer Inst 2003, 95(17):1330-1335.

16. Carbone A, Gloghini A: HHV-8-associated lymphoma: State of the art review. Acta Haematol 2007, 117(3):129-131

17. Karcher D, Alkan S: Human herpes virus 8 associated body-cavity based lymphomas in human immunodeficiency virus infected patients: a unique B cell neoplasm. Hum Pathol 1997, 28(7):801-808.

18. Adiguzel C, Bozkurt SU, Kaygusuz I, Uzay A, Tecimer T, Bayik M: Human herpes virus 8-unrelated primary effusion lymphoma-like lymphoma: report of a rare case and review of the literature. APMIS 2009, 117(3):222-229.

19. Carbone A, Gloghini A: PEL and HHV8-unrelated effusion lymphomas: classification and diagnosis. Cancer Cytopath 2008, 114(4):225-227.
20. Mbulaiteye SM, Biggar RJ, Goedert JJ, Engels EA: Pleural and peritoneal lymphoma among people with AIDS in the United States. J Acquir Immune Defic Syndr 2002, 29(4):418-421.

21. Cesarman E, Chang Y, Moore PS, Said JW, Knowles DM: Kaposi's sarcomaassociated herpesvirus DNA sequences in AIDS body cavity based lymphomas. N Eng J Med 1995, 332(18):1186-1191.

22. Schultz T: KSHV/HHV8-associated lymphoproliferations in the AIDS setting. Euro J Cancer 2001, 37(10):1217-1226.

23. Nador RG, Cesarman E, Chadburn A, Dawson DB, Ansari MQ, Sald J, Knowles DM: Primary effusion lymphoma: a distinct clinicopathologic entity associated with Kaposi's sarcoma-associated herpesvirus. Blood 1996, 88(2):645-656

24. Yiakoumis X, Pangalis GA, Kyrtsonis MC, Vassilakopoulos TP, Kontopidou FN, Kalpadakis C, Korkolopoulou P, Levidou G, Androulaki A, Siakantaris MP, Sachanas S, Andreopoulos A: Primary effusion lymphoma in two HIVnegative patients successfully treated with pleurodesis as first-line therapy. Anticancer Res 2010, 30(1):271-276.

25. Mantina H, Wiggill TM, Carmona S, Perner Y, Stevens WS: Characterization of Lymphomas in a high prevalence HIV setting. J Acquir Immune Defic Syndr 2010, 53(5):656-660.

26. Dabaghmanesh N, Matsubara A, Miyake A, Nakano K, Ishida T, Katano H, Horie R, Umezawa K, Watanabe T: Transient inhibition of NF-kappaB by DHMEQ induces cell death of primary effusion lymphoma without HHV8 reactivation. Cancer Sci 2009, 100(4):737-746.

27. Takahashi-Makise N, Suzu S, Hiyoshi M, Ohsugi T, Katano H, Umezawa K, Okada S: Biscoclaurine alkaloid cepharanthine inhibits the growth of primary effusion lymphoma in vitro and in vivo and induces apoptosis via suppression of the NF-kappaB pathway. Int J Cancer 2009, 125(6):1464-1472.

doi:10.1186/1752-1947-5-60

Cite this article as: Tumwine et al:: Primary effusion lymphoma associated with Human Herpes Virus-8 and Epstein Barr virus in an HIVinfected woman from Kampala, Uganda: a case report. Journal of Medical Case Reports 2011 5:60.

\section{Submit your next manuscript to BioMed Central and take full advantage of:}

- Convenient online submission

- Thorough peer review

- No space constraints or color figure charges

- Immediate publication on acceptance

- Inclusion in PubMed, CAS, Scopus and Google Scholar

- Research which is freely available for redistribution

Submit your manuscript at www.biomedcentral.com/submit
C Biomed Central 